\title{
An Evaluation of Building Our Nation's Daughters (BOND): Improving Black Single Mother-Daughter Relationships and Well-Being
}

\author{
Rebecca L. Fix $\mathbb{D}^{1}$ \\ Accepted: 24 November 2021 / Published online: 12 January 2022 \\ (c) The Author(s), under exclusive licence to Springer Science+Business Media, LLC, part of Springer Nature 2021
}

\begin{abstract}
Although single mothers report being most concerned about financial costs, the needs of these mothers and their children are more extensive. The current study evaluated a program for Black single mothers with adolescent daughters that emphasized the mother-daughter relationship and coping skills to promote well-being. The program is Building Our Nation's Daughters (BOND). Individual interviews were conducted with five mothers and five daughters who had participated in BOND. Interviews were conducted online during the COVID-19 pandemic. Interviews were audio recorded and transcribed to allow for coding and analysis of qualitative data. Mothers and daughters also verbally provided numeric outcome ratings specific to select outcomes. Mother and daughter well-being improved based both on self-report and report of the other member of the dyad (i.e., mother for daughter, daughter for mother). Results suggest programs like BOND have the capacity to improve mood and strengthen the mother-daughter relationship through development of coping skills and conflict resolution skills. The evaluated program improved mother and daughter well-being in part through skills building, but importantly through improvement in the mother-daughter relationship, as well. BOND could be used as a template for similarly situated families. For example, the program could be modified to address the needs of single father households and single caregiver households with adolescent boys.
\end{abstract}

Keywords Family $\cdot$ Parenting $\cdot$ Intervention $\cdot$ Caregiver $\cdot$ Individual interview

\section{Highlights}

- There is a need to expand our foci for interventions specific to Black single mothers to include wellness and their parentchild relationship.

- The current study demonstrated preliminary efficacy of the Building Our Nation's Daughter program in individual and dyadic outcomes.

- Interviewed mothers in the program described improved well-being, namely through a strengthened relationship with their daughter.

- During interviews with adolescent daughters of single mothers, the program improved coping skills and conflict resolution.

- The Building Our Nation's Daughter program is a promising intervention for Black single mothers with adolescent daughters.

Rebecca L. Fix

rebecca.fix@jhu.edu

1 Department of Mental Health, Johns Hopkins Bloomberg School of Public Health, Johns Hopkins University, $415 \mathrm{~N}$ Washington Street, Baltimore, MD 21231, USA
In many urban areas, a majority of children live in single caregiver (typically single mother) households; Black families are the most likely to be classified as single mother households (U.S. Census Bureau, 2021; Vespa et al., 2013). Data indicate that single mothers are most concerned about housing, daycare, and other financial costs (Griffin \& Elliot, 2018). However, while most programing for single mothers focuses exclusively on providing 
financial resources, these mothers - and their children have needs extending beyond those that are financial/economic (Broussard, 2010). The current study included interviews with single mothers and their adolescent daughters who were participating in a program created to improve Black single mother-adolescent daughter relationships - Building Our Nation's Daughters (BOND). The primary purpose of the current study was to preliminarily evaluate how the BOND program (that provided holistic services: financial, mental health support, parenting skills, communication skills, and wellness education) for single mothers with adolescent daughters in Baltimore City impacted Black single mother and adolescent daughter well-being and the mother-daughter relationship.

\section{Extended Needs of Black Single Mothers and Their Adolescent Daughters}

Single mothers have elevated rates of mental and physical health problems - or reduced overall well-being (Broussard, 2010; Crosier et al., 2007) and may thus have diminished parental relationship quality and parenting quality (Waldfogel et al., 2010). As a consequence, the mental and physical health of their children suffers (Jayakody \& Stauffer, 2000), and children of single mothers are more likely to engage in risky (e.g., unprotected sex, fighting) and delinquent behavior (Fix \& Burkhart, 2015; Kotchick et al., 1999; Waldfogel et al., 2010). Regardless of whether mental and physical health problems among single mothers and their children are functionally a cause or a consequence of economic disadvantage, experts recognize a need for mental health services to improve both economic and family outcomes (Jayakody \& Stauffer, 2000; Maldonado \& Nieuwenhuis, 2015; Thomson \& McLanahan, 2012). There is also a demonstrated need for social support to improve wellness and other outcomes like economic stability (Harandi et al., 2017), particularly for caregivers in single parent families (Martin-West, 2019; Mortelmans \& Verheyen, 2011). In sum, programming that prioritizes promotion of single mother mental and physical should (1) facilitate development and regular practice of coping skills and (2) strengthen existing social support systems.

Adolescence is a developmental period during which youth become more autonomous and begin separating themselves from their families. Still, the role of family particularly mothers - is critical in fostering healthy development (Keizer et al., 2019; Sieving et al., 2017). Strong parent-child relationships are especially important during adolescence for well-being and health (Sieving et al., 2017). Moreover, during adolescence, it is typical for a youth to begin anticipating and responding to the needs of their family members, thus serving as a source of support and care for family members themselves (Wei et al., 2020).
These developmental markers render adolescence a great time for intervention to strengthen the mother-daughter relationship while helping daughters thrive.

\section{Family Interaction Theory and the Family Resilience Framework}

Two theories can illuminate some of the important components of programs or interventions for families to improve general wellness and mental and physical health. These include family interaction theory and the family resilience conceptual framework (Brook et al., 1990; Walsh, 2016). Family interaction theory (Brook et al., 1990) is grounded in a multilevel systems orientation and recognizes the inextricable connection between family members and influence of each family member on the others within their family system. Family interaction theory would posit that wellbeing and health of one family member influences all other members of the system. In single-caregiver families, the well-being and health of the caregiver are even more integral to the well-being and health of other family members (e.g., Maldonado \& Nieuwenhuis, 2015; Waldfogel et al., 2010). Further, family interaction theory emphasizes the importance of parent-child attachment and the parent-child relationship (especially that between mother and child) on outcomes for both the parent and child. So, according to family interaction theory, warm and nurturing relationships between mothers and their daughters will improve outcomes for mothers and reduce risk for daughter mental and behavioral health problems. Interventions designed to improve outcomes for single mothers and adolescent daughters should be guided by this theory and include communication skill development and other components specifically aiming to strengthen the mother-daughter bond.

In recognizing the interconnectedness of family members with one another, the family resilience framework suggests that belief systems, organizational processes, and communication processes within the family are critical in the development of family resilience (Walsh, 2016). A family systems perspective broadens attention to resources for individual resilience throughout the family network of relationships. The concept of family resilience refers to the family as a functional system that is both impacted by highly stressful events and social contexts, and resilience facilitates the positive adaptation of all members and strengthens the family unit.

\section{Responding to the Needs of Black Single Mother Families}

In the United States, there is a paucity of efficacious familybased approaches to mental and behavioral health, and this 
lack of resources extends to Black single-mother families. Given the integral role of family relationships described above, interventions that prioritize responding to the family system is critical. It is especially common for mothers to describe having strong bonds with their daughters, especially their adolescent daughters (Snyderman \& Streep, 2002), suggesting that programming simultaneously involving mothers and their adolescent daughters might be a potent mechanism for promoting well-being among mothers. Moreover, powerful and dynamic mother-daughter relationships are also frequently associated with improved daughter well-being and protect against daughters' delinquent behavior and behavioral health problems like substance use and participation in risky sexual activity (Allen et al., 2016; Coakley et al., 2017; Janssen, Eichelsheim, Deković, \& Bruinsma, 2017; Johnson, 2016; Llorca, Cristina Richaud, \& Malonda, 2017). Altogether, research supports the development of programs that simultaneously meet the individual wellness needs of single mothers and adolescent daughters while also promoting a stronger mother-daughter relationship.

Many existing programs for - and research on - caregivers/ parents (often mothers) with adolescent daughters focus on daughter substance use and sexual risk behavior (Donenberg et al., 2020; Romo et al., 2014; Schinke et al., 2011). One promising computer-based and gender-specific intervention targeting substance use that included both single mothers and mothers parenting with a partner demonstrated promising outcomes and was associated with significant improvement in parent-daughter communication and selfefficacy in daughters. This program demonstrated the power of offering an accessible (computer-based) and genderspecific intervention. Another mother-daughter intervention that was designed to reduce risky sexual behavior and STIs among Black adolescent daughters has demonstrated promise in achieving its aims, as well (Donenberg et al., 2020). Altogether, family-specific, race-informed, and motherdaughter interventions appear to be an effective strategy for addressing needs of adolescent daughters. However, there are no known evidence-based programs that emphasize the single mother-daughter relationship, and no known evidence-based programs focus on improving mother (let alone single mother) wellness.

\section{Current Study}

Black single mothers families with adolescent daughters are in particular need of programming to strengthen the motherdaughter relationship. Integrating family interaction theory and the family resilience framework, Building our Nation's Daughters (BOND) incorporated theoretically-derived elements of social learning, attachment, and other factors that contribute to family resilience. The BOND nonprofit organization was founded in 2015 to improve mother-daughter relationships, their mental and physical health, ensure equitable access to opportunity, and reduce daughter risky behaviors. BOND provides therapeutic, socioeconomic, and educational services to single mothers with daughters age $12-17$. Such services are provided to build a strong motherdaughter relationship along with improved mental and physical health of the mother and their daughter(s).

No known studies have provided interventions designed to strengthen mother-daughter relationships for Black families with preadolescent/adolescent daughters. In response, the current study focused on two research questions. (1) How does participation in BOND influence mother and daughter well-being (i.e., use of coping skills, mood, stress, problem-solving)? (2) How does participation in BOND influence the single mother-adolescent daughter relationship?

\section{Subjects and Method}

\section{BOND Curriculum}

In 2015, Building Our Nation's Daughters (BOND), Inc. was created to improve (1) relationships between Black single mothers and their adolescent daughters, (2) the academic and social-emotional wellbeing of participating daughters, and (3) personal development for participating single mothers. The mission of BOND is to engage, mentor and develop Black single mothers and their daughters and foster the economic mobility of these two generations. Successful family interventions to adolescent behavior change are: engaging for caregivers and adolescents, gender-specific, affordable, and meet scheduling needs of all participants (Schinke et al., 2011). Therefore, BOND programming was developed incorporating these best practices.

Before the COVID-19 pandemic (when BOND was taking place in person), $2 \mathrm{~h}$ BONDing experiences were held in person twice a month. Since the COVID-19 pandemic, BOND programming is now offered virtually on a weekly basis, with $2 \mathrm{~h}$ sessions that did not include the group meal for a while, but after COVID-19 restrictions were reduced, BOND included monthly meals delivered to participants' homes during sessions. Each $2 \mathrm{~h}$ BOND session consists of first a $45 \mathrm{~min}$ group therapy session followed by a $30 \mathrm{~min}$ meal and a $45 \mathrm{~min}$ educational activity. Group therapy sessions all begin with a circle exercise where mother-daughter dyads are encouraged to respond to a prompt provided by BOND leadership. The remainder of this portion of the session centers around strengthening communication skills and problem-solving skills within dyads but in a group setting. The meal portion of the session 
Table 1 Overview of Building Our Nation's Daughters (BOND) Curriculum and Activities

\begin{tabular}{ll}
\hline Activity Topic & Content \\
\hline Communication Skills & $\begin{array}{l}\text { Learn assertive communication strategies and engage in activities to } \\
\text { improve mother-daughter communication }\end{array}$ \\
$\begin{array}{l}\text { Socio-Emotional Support } \\
\text { Health and Fitness Education }\end{array}$ & $\begin{array}{l}\text { Learn about nutrition, healthy cooking on a budget, and strategies and } \\
\text { importance of staying physically fit }\end{array}$ \\
Academic Supports & Learn about financial aid and tutoring resources \\
Cultural Development & Learn about Black history and African heritage \\
Financial Supports & Learn about resources in Baltimore and money management \\
Service Learning & Encourage program participants to volunteer in BOND activities \\
Art Appreciation & Learn about aesthetics in applied and performance arts \\
\hline
\end{tabular}

is unstructured - participants are encouraged to intermingle, in part to foster social support systems. For the final $45 \mathrm{~min}$ of each session, one of the primary educational content areas is discussed and an active learning/exercise is used to help develop skills and solidify knowledge for mothers and daughters alike.

Eight education content areas are included in the BOND curriculum (see Table 1). Each year programming focuses on both hard and soft skill development - as well as increases in knowledge - including literacy, effective communication strategies, social-emotional skills, art, math, and financial wellness. Racial and gender empowerment are also integrated into all content (Donenberg et al., 2020). BOND programming is ongoing, providing support for Black single mothers and daughters in social-emotional, academic, and economic growth. Because BOND targets families with limited resources, referrals to social services are prioritized along with events like a Thanksgiving meal distribution.

BOND currently works in partnership with community partners schools - two middle schools and one combined middle-high school. BOND participants are recruited through programming at the school and then voluntarily enroll after attending an interest meeting. Enrollment starts as early as grade 5 and extends through grade 12 . BOND programming was initiated in Baltimore in part because $65 \%$ of children live in single-caregiver households; furthermore, most of these households are Black single-mother households (Baltimore City Health Department, 2017).

\section{Participants and Procedure}

Individual interviews were conducted with mothers and daughters by one of two trained interviewers. One interviewer self-identified as a Black/African American cisgender woman who is currently married with three children (two of whom are adolescents). She was born and raised in Baltimore (the location of the current study) and connected with some participants over a shared faith/belief system. The second interviewer self-identified as an Asian biracial cisgender woman who is recently divorced with one young child from the larger geographic region but not Baltimore.

Recruitment occurred - and interviews were conducted during the COVID-19 pandemic. Thus, recruitment materials were distributed to all current BOND participants through email and social media. Both members of BOND mother-daughter dyads were eligible to participate in our study, but their participation occurred independent of their daughter or mother. Participants were compensated with a $\$ 25$ gift card for their time. Experts in qualitative research methods indicate meta themes can be derived from samples of six participants (Baker \& Edwards, 2012; Guest et al., 2006). It is also important to recognize that perhaps the most important aspect of qualitative research however is the "quality of the analysis and the dignity, care and time taken to analyze interviews, rather than quantity" (Baker \& Edwards, 2012). We were able to recruit five mothers and five daughters. To date, all former and current BOND participants have identified as African American/Black women and girls. Participating mother ages range from 32 to 47 years old, and participating daughter ages range from 12 to 17 years old. BOND program staff and volunteers all identify as Black. All participants in the current study had been in BOND for a minimum of 5 months, identified their race as Black and ethnicity as non-Latinx, and resided in Baltimore, MD. Of the daughters, ages were 12, 12, 13, 14, and 15 . Mothers identified their ages as $35,35,35,36$, and 37. All mothers identified their sexual orientation as straight/heterosexual; concerning relationship status, three mothers identified as single-never married, one as single and divorced, and other described their relationship status as other. Three of the mothers reported the lowest range of income (\$0-20,999), one reported an income of $\$ 21,000-40,999$, and another reported an income in the rage of $\$ 61,000-80,999$. Three participants had earned their high school diploma, one had earned an associates degree, and one earned a bachelors degree. All participants provided informed consented orally and were informed they could terminate their participation or ask for their data to be 
excluded from any research products at any point without losing the honorarium and without any other penalty.

A multiple-step process was used to develop individual interview question stems. The ultimate product reflected a shared understanding of the goals of the individual interviews and ensured item stems achieved those goals. Finally, the team engaged in multiple rounds of review to ensure items were clear, concise, and open-ended before settling on the specific item stems. We also included questions that asked participants to rate outcomes from BOND on a scale of 1 to 10 (e.g., mood, ability to cope with stress).

Individual interviews were audio-recorded and transcribed for analytic purposes. During individual interviews, two experienced Research Assistants who both identify as biracial used a semi-structured interview guide to measure how BOND successfully meets participant needs and to identify areas for improvement. Questions were designed to understand how participants' experiences with BOND differs from that of their other opportunities or experiences through the social services system and gauged the extent to which participants behavior, perceptions, and attitudes have changed due to BOND programming. An institutional review board at the author's university approved this study.

\section{Data Analysis}

A codebook was developed using an inductive approach through Grounded Theory (Strauss \& Corbin, 1997) such that transcripts were reviewed for emerging concepts and common patterns. Coding themes and subthemes were modified as needed to ensure that the concepts accurately reflected the assigned category. This process was completed until all data were accounted for within the main themes and subthemes. Themes and subthemes in the resultant codebook were operationally defined to promote interrater reliability in coding.

Interrater reliability was tested by having both researchers independently code a randomly selected interview and compare codes assigned. During this process, disagreements on code assignment were discussed and definitions of coding themes were refined as needed. This process was deemed complete after one interview with mothers and one full interview with daughters was coded, as the two coders established an $83 \%$ and $87 \%$ agreement at this point, respectively (Miles \& Huberman, 1994). Team members then independently coded the remaining interview transcripts (Dedoose Version 8.1.10, 2018).

\section{Results}

Quantified BOND self-ratings and associated outcomes for mothers and daughters are displayed in Table 2. Qualitative themes and quotes providing examples of statements from
Table 2 Mother and Daughter BOND Outcome Ratings

\begin{tabular}{lll}
\hline Outcome Variable & $M$ & Range \\
\hline Daughters & $n=5$ & \\
Coping with Stress & 7.5 & $6.0-9.5$ \\
Mood & 6.8 & $5.0-9.0$ \\
Resolving Conflict & 7.6 & $4.0-8.0$ \\
Academic Performance & 8.2 & $5.0-10.0$ \\
Relationship Before BOND & 6.2 & $4.0-9.0$ \\
Relationship After BOND Participation & 8.0 & $7.0-9.0$ \\
BOND Program Satisfaction & 8.9 & $8.0-10.0$ \\
Mothers & $n=5$ & \\
Coping with Stress & 8.2 & $6.0-10.0$ \\
Mood & 8.4 & $8.0-10.0$ \\
Resolving Conflict & 7.0 & $5.0-10.0$ \\
Relationship Before BOND & 4.2 & $1.0-7.0$ \\
Relationship After BOND Participation & 7.6 & $6.0-9.0$ \\
BOND Program Satisfaction & 9.6 & $9.0-10.0$ \\
\hline
\end{tabular}

Participants rated the above outcomes regarding how they believed BOND impacted them on a scale of 1 (lowest/poorest) to 10 (highest/ best)

mothers and daughters exemplifying these themes are included below.

\section{Mother Outcomes}

Mothers described improved well-being due to their participation in BOND. One mother said:

"Before $[\mathrm{BOND}] . .$. my mindset was terrible. I would always talk down about myself. Not really believing myself, and the sessions that I did go to, the things that they were asking us to do, it really opened up my mind for me to think and manifest, and it just helped." [M3]

Another example of recognized improvement occurred when this mother described better strategies for coping with stress: "[Before] I couldn't deal with it. I didn't deal with it in a positive way before... I'm still growing with it now, but I feel like it's gotten a lot better" [M3]. Daughters also described how BOND impacted their mothers' well-being. As an example of such statements, one daughter said, "I think [BOND]'s impacted [my mother] a lot, because now she can come and talk to me if she's sad, and, like, if she sees me sad, she'll ask me what's wrong" [D1]. Another daughter said about her mother:

"I think she been able to at least let herself be a little bit more open, even though she still has some old bad habits, that she's trying to break through of, 
because it's not easy. And it's like, she's struggling to do that too" [D5].

\section{Daughter Outcomes}

Daughters also described improved well-being as a result of their participation in BOND. As examples of this phenomenon, one daughter said, "[BOND] helped me, and it calms me down" [D2], and another said, "I've dealt with [stress] better than before" [D3]. All participating daughters also reported BOND helped in their ability to resolve conflict with people. One daughter discussed how her behavior focused on resolving conflict differs now versus before BOND:

"[Now in BOND I] take deep breaths when [I'm] stressed...Before, if I'm stressed, like, if I'm angry at somebody, it's the way people act around me it's quick. Either fuss at 'em back or if they put they hands on you put your hands on "em back" [D3].

Three of the daughters described verbally and physically fighting less and using skills learned during BOND to fight less. One daughter said:

"[BOND] helped me... in school, there's so many things that happen... Fights happen twice, or three times a day. Something else ended up happening... my teachers at [redacted] would always yell at me, and my [classmates]...[someone] said that she will fight me in school... So, I calmed myself down. I left the class and calmed myself down" [D2].

Another daughter described using the same technique to resolve a situation that could have escalated into a fight saying, "[I have learned] removing myself. And not talking to certain people that, like, would get me in trouble" [D1].

One of the mothers also described getting into physical fights less often following BOND saying,

"[description of fight before BOND]... 'Will you let me know what you're fighting for?'... [BOND's] allowing me to really talk to people to make them understand your actions... it's allowing me to stay calm and talk things out without, you know, being craziness" [M3].

Mothers described how BOND involvement positively influenced their daughters. Said one mother:

"Well, for me and her, [BOND] helped her to understand and to listen... I didn't know how she feeling, where she coming from, and there's a little issue we might had where we sit there and talk about it...The issue, what's going on, what can we work out... This is the right program for me and my daughter" [M5].

\section{Mother-Daughter Relationship}

Mothers and daughters were each asked whether and how their relationship was impacted by BOND. Most mothers described significant improvements saying things like, "my daughter and I both agreed that we need to spend more time with each other" [M2], "everything healthier" [M5], and "Our communication has improved, um, we understand each other better, and we've learned I guess to deal with each other in a different way" [M1]. This mother also used a comparative statement to demonstrate growth in her relationship with her daughter, "we weren't really communicating effectively before BOND...We weren't on the same page" [M1]. BOND also helped one mother recognize that her relationship with her daughter is continually evolving and dynamic, stating, "we're a work in progress" [M4].

Three daughters made remarks about improvements in their relationships with their mothers. This exemplified by one daughter's statement, "I wouldn't have talked to her about certain things that's going on... [Now] I can go to her about situations, and not being scared to talk to her about things" [D1]. One daughter even described how BOND has strengthened her resolve to "start knowing more about my mother" [D2]. Another daughter described how she imagined her relationship with her mother will continue to improve as they participate in BOND saying, "I think it would be healthier because we would have like other skills and things" [D4].

During COVID-19, two daughters described difficulties in their relationship with their mothers. Said one daughter about her current relationship with her mother, "we don't actually talk in person sometimes. I normally talk to her through text. When she's either at work, or somewhere else" [D2]. The other daughter who expressed similar frustrations about wanting to continue strengthening her relationship with her mother saying, "it's not fully there just yet. We still have our ups and downs... I would like to know more about her" [D4].

\section{Relationships with Others}

Benefits of relationship skills building was described broadly in some interviews with mothers as blending into other relationships or areas of their life. Said one mother:

"It's given me that confidence to be able to express myself based off of what we did, letting people, letting each other know how we feel...So it definitely 
allowed me to push it, like trickle that on into my personal life... I don't have a boyfriend, but I do have a friend... now I can use what I learned in BOND” [M3].

Another mother described how she found BOND skills so valuable that she taught them to her friends with daughters:

"Things that I learn in BOND in share with my friends that also have daughters, so it has strengthened their relationship... the things that I've learned about dealing with my daughter, I can then use those in my friendships as well" [M1].

One daughter described using BOND skills with her friends at school: "at first, I just seen myself as, like, not really listening to people, what they're saying...so, now, I'm making an effort [to listen]" [D1].

\section{Discussion}

The current study evaluated a program - Building Our Nation's Daughters (BOND) - that prioritized Black single mother and daughter relationships and wellness. Outcomes of interest in the current study extended beyond those typically addressed for Black adolescent girls with single mothers to improved mood and well-being. Overall, mothers and daughters reported improvements in their wellbeing, additional outcomes, and their mother-daughter relationship following BOND participation.

Results suggest the BOND program has the capacity to improve mother and daughter mood and well-being, and daughter academic performance, through development of coping skills and conflict resolution skills. This finding aligns with existing research first because research demonstrates that the parent-child relationship may be negatively impacted by the high rates of mental and physical health problems among single mothers (Broussard, 2010; Crosier et al., 2007; Waldfogel et al., 2010). Second, because family members are interconnected (Brook et al., 1990; Sieving et al., 2017), when parents are overburdened and stressed, their children's mental and physical health is impacted (Fix \& Burkhart, 2015; Jayakody \& Stauffer, 2000; Kotchick et al., 1999; Thomson \& McLanahan, 2012; Waldfogel et al., 2010). Therefore, interventions should simultaneously target mother and daughter skill development to reduce stress and improve parent and youth mental and physical health. In the BOND program - Black single mothers and their daughters were the target population; results further demonstrated economic disadvantage should also be addressed to reduce stressors.
Given the importance of modeling and social learning on skill-building, mothers' ability to resolve conflict effectively and safely is important. At least one mother explicitly described how she stopped fighting since she began meaningfully participating in BOND. Three of five daughters also described fighting less due to BOND's emphasis on relationship skill building. Two daughters indicated they did not get into fights before BOND, so did not have room for improvement on this outcome measure. Ultimately, the BOND program relies upon - and focuses on strengthening the interconnectedness of family members through skills building to improve outcomes for both the mother and daughter (Brook et al., 1990; Sieving et al., 2017).

"I like that every Thursday, me and my mother get together to do stuff because we got to do BOND" this statement from one of the BOND daughters emphasizes how BOND not only positively impacted individual mother and daughter well-being, but also improved the motherdaughter relationship. Indeed, mothers talked about an improved mindset and reduced stress levels, and their daughters even named their mothers' increased use of emotion-focused coping skills in their interviews. Daughters also discussed improved well-being due to their participation in BOND including learning and using relaxation strategies to cope with stress and improved conflict resolution with peers.

Further, most mothers and daughters described improvements in their mother-daughter relationship. Relationships with parental figures are important for child and adolescent development and well-being (Hair et al., 2008; Masarik \& Conger, 2017). The parent-child relationship is particularly important for well-being children of single caregivers (Dinisman et al., 2017), and can significantly impact violence and conflict in daughter's romantic relationships (Maas et al., 2010). BOND's success in developing skills that strengthened single mother-daughter relationships offers a promising means of promoting wellbeing in this family context and might reduce adolescent risk behaviors like fighting with peers and experiencing violence in romantic relationships (yet further research is needed to evaluate the effectiveness of BOND programming on adolescent risk behaviors).

Finally, the BOND program is designed to strengthen social support networks for participants, which is especially important for single caregivers (Martin-West, 2019). While conversations did not directly ask about changes to social support systems outside of the mother-daughter relationship, participants did describe how BOND strengthened their social support systems, with mothers naming romantic partners and friends and daughters naming friends and peers. Given the strong known association between social support and mental health (Harandi et al., 2017), our findings demonstrate the importance of including group work for both Black single 
mothers and their adolescent daughters in programming designed to promote mental and physical health for single mothers and daughters - and their relationship. Future work should seek to identify the mechanisms through which social support is increased in BOND.

\section{Implications}

Findings from the present study have several implications for those interested in improving overall mental health among Black single mothers, their adolescent daughters, or both. First, our research highlights that professionals who work with Black single mothers should expand their focus beyond economic disadvantage and food insecurity to be more holistic in scope. While a critical need for Black single mothers is to achieve financial stability, they benefit from strong connections with their children; their children also benefit from parental well-being and a strong mother-child relationship (Maldonado \& Nieuwenhuis, 2015; Walsh, 2016; Wei et al., 2020). Programming for single mothers should either directly provide or offer access to external resources that can foster single mothers' mental health and strengthen existing social support systems (e.g., Harandi et al., 2017). Further encouraging a healthy and strong mother-daughter relationship is also advised through evidence-based approaches like mindful parenting practices (Chen et al., 2019; Russell \& Guite, 2020).

Our findings also emphasize the need for a more ecologically oriented approach to mental health treatment. Therapists and other professionals working to improve mental health among Black single mothers or Black adolescent girls should consider a family-centered approach, even in addressing seemingly individual-level presenting problems. Evidence-based programming for single mothers and their adolescent daughters often targets the family system to meet the needs of daughters (Donenberg et al., 2020; Romo et al., 2014; Schinke et al., 2011). Naturally, improved mother-daughter relationships likely translate to better outcomes for participating mothers as well, and this preliminary evaluation of BOND suggests as much.

Further extending the ecological systems lens, BOND programming - or programming incorporating key elements of BOND - could be implemented at a school or community level. Existing programming has a demonstrated effect on positive parenting behaviors and that strengthens the parentchild relationship such as the Triple P-Positive Parenting Program (Sanders, 2012) and Parent-Child Connect (Wang et al., 2021). While cultural adaptations might be important for buy-in, engagement, and efficacy as demonstrated in Wang et al., 2021 work, such programs lay the groundwork for a holistic approach that can strengthen family systems while simultaneously improving mental health and reducing risk for caregivers and children alike. Such programming could also be integrated into existing programs offered through community organizations like in community engagement centers and after school programs.

\section{Limitations and Future Directions}

The current study was limited in that we had a small sample size - recruitment began during COVID-19 and the online interviewing format is not ideal for qualitative research. However, consistent themes were able to be extracted from our data in part because best practices in our methodological process were employed (Daniels et al., 2019). While BOND is currently concentrated in Baltimore City, it is applicable to Black families in other urban areas. The study sample only included Black single mothers and daughters in urban areas so some curriculum components may need to be modified or further examined understand how they might influence members of families with different characteristics and experiences- for example - individuals in single father families.

Future research should recruit larger sample sizes and interview participants in person. Further, this evaluation was conducted while the BOND program was being provided virtually. Computer delivery of programs can increase accessibility of programming, so follow-up research is needed to better understand program effects for in-person BOND programming. Additionally, collecting more quantitative data to expand upon our observed qualitative outcomes would improve our understanding of benefits of BOND and ways to improve upon the curriculum and program overall. Given the promise of BOND as a more holistic intervention for improving mother and daughter well-being and for strengthening mother-daughter relationships, the program could be modified for use in other contexts and family structures. Finally, the use of longitudinal randomized controlled trials is warranted to elucidate mechanisms through which BOND is effective in achieving desired outcomes.

\section{Ethics Approval}

The interview guide and ethical approval was obtained from the Institutional Review Board at the Johns Hopkins University - Bloomberg School of Public Health. All procedures used in this study adhere to the tenets of the Declaration of Helsinki. Individual participants in this study provided consent to have their personal data gathered and used for research and publication purposes.

\section{Data Availability}

Information on data can be obtained by contacting the author. 
Acknowledgements The author would like to acknowledge Ericka Muempfer and Christina Knepper for their assistance with data collection and management. This work would not be possible without these incredible professionals.

Funding This work was supported by the Bloomberg American Health Initiative.

\section{Compliance with Ethical Standards}

Conflict of Interest The author declares that the study was conducted in the absence of any commercial or financial relationships that could be construed as a potential conflict of interest.

Publisher's note Springer Nature remains neutral with regard to jurisdictional claims in published maps and institutional affiliations.

\section{References}

Allen, M. L., Garcia-Huidobro, D., Porta, C., Curran, D., Patel, R., Miller, J., \& Borowsky, I. (2016). Effective parenting interventions to reduce youth substance use: A systematic review. Pediatrics, 138(2), e20154425.

Baltimore City Health Department (2017). Baltimore City 2017 Neighborhood Health Profile. health.baltimorecity.gov2017.

Baker, S. E., \& Edwards, R. (2012). How many qualitative interviews is enough. National Centre for Research Methods Review Paper. (pp 3-6). Retrieved from http://eprints.ncrm.ac.uk/2273.

Brook, J. S., Brook, D. W., Gordon, A. S., Whiteman, M., \& Cohen, P. (1990). The psychosocial etiology of adolescent drug use: a family interactional approach. Genetic, Social, and General Psychology Monographs, 116(2), 111-267.

Broussard, C. A. (2010). Research regarding low-income single mothers' mental and physical health: A decade in review. Journal of Poverty, 14(4), 443-451.

Chen, Y., Peng, X., Zhou, X., \& Fu, Y. (2019). The impact of mindful parenting on children's shyness and social indifference: the mediating role of parent-child relationship. Studies in Preschool Education, 05, 72-80. https://doi.org/10.13861/j.cnki.sece.2019.05.007.

Crosier, T., Butterworth, P., \& Rodgers, B. (2007). Mental health problems among single and partnered mothers. Social psychiatry and psychiatric epidemiology, 42(1), 6-13.

Coakley, T. M., Randolph, S., Shears, J., Beamon, E. R., Collins, P., \& Sides, T. (2017). Parent-youth communication to reduce at-risk sexual behavior: A systematic literature review. Journal of Human Behavior in the Social Environment, 27(6), 609-624.

Daniels, N., Gillen, P., Casson, K., \& Wilson, I. (2019). STEER: Factors to consider when designing online focus groups using audiovisual technology in health research. International Journal of Qualitative Methods, 18, 1609406919885786.

Dinisman, T., Andresen, S., Montserrat, C., Strózik, D., \& Strózik, T. (2017). Family structure and family relationship from the child well-being perspective: Findings from comparative analysis. Children and Youth Services Review, 80, 105-115.

Donenberg, G. R., Kendall, A. D., Emerson, E., Fletcher, F. E., Bray, B. C., \& McCabe, K. (2020). IMARA: A mother-daughter group randomized controlled trial to reduce sexually transmitted infections in Black/African-American adolescents. PLoS ONE, 15(11), e0239650.

Fix, R. L., \& Burkhart, B. R. (2015). Relationships between family and community factors on delinquency and violence among African American adolescents. Race and Justice, 5(4), 378-404. https://doi.org/10.1177/2153368715583134.
Griffin, A., \& Elliot, K. (2018). BOND Survey Results. Building Our Nation's Daughters (BOND).

Guest, G., Bunce, A., \& Johnson, L. (2006). How many interviews are enough? An experiment with data saturation and variability. Field methods, 18(1), 59-82.

Hair, E. C., Moore, K. A., Garrett, S. B., Ling, T., \& Cleveland, K. (2008). The continued importance of quality parent-adolescent relationships during late adolescence. Journal of Research on Adolescence, 18(1), 187-200.

Harandi, T. F., Taghinasab, M. M., \& Nayeri, T. D. (2017). The correlation of social support with mental health: A meta-analysis. Electronic Physician, 9(9), 5212.

Janssen, H. J., Eichelsheim, V. I., Deković, M., \& Bruinsma, G. J. (2017). Sex differences in longitudinal pathways from parenting to delinquency. European Journal on Criminal Policy and Research, 23(4), 503-521.

Jayakody, R., \& Stauffer, D. (2000). Mental health problems among single mothers: Implications for work and welfare reform. Journal of Social Issues, 56(4), 617-634.

Johnson, J. W. (2016). "All I do is win... no matter what": Lowincome, African American single mothers and their collegiate daughters' unrelenting academic achievement. The Journal of Negro Education, 85(2), 156-171.

Keizer, R., Helmerhorst, K. O., \& van Rijn-van Gelderen, L. (2019). Perceived quality of the mother-adolescent and father-adolescent attachment relationship and adolescents' self-esteem. Journal of Youth and Adolescence, 48(6), 1203-1217.

Kotchick, B. A., Dorsey, S., Miller, K. S., \& Forehand, R. (1999). Adolescent sexual risk-taking behavior in single-parent ethnic minority families. Journal of Family Psychology, 13(1), 93.

Llorca, A., Cristina Richaud, M., \& Malonda, E. (2017). Parenting, peer relationships, academic self-efficacy, and academic achievement: Direct and mediating effects. Frontiers in Psychology, 8, 2120.

Maas, C. D., Fleming, C. B., Herrenkohl, T. I., \& Catalano, R. F. (2010). Childhood predictors of teen dating violence victimization. Violence and Victims, 25(2), 131-149.

Maldonado, L. C., \& Nieuwenhuis, R. (2015). Family policies and single parent poverty in 18 OECD countries, 1978-2008. Community, Work \& Family, 18(4), 395-415.

Martin-West, S. (2019). The role of social support as a moderator of housing instability in single mother and two-parent households. Social Work Research, 43(1), 31-42.

Masarik, A. S., \& Conger, R. D. (2017). Stress and child development: A review of the Family Stress Model. Current opinion in psychology, 13, 85-90.

Miles, M. B., \& Huberman, A. M. (1994). Qualitative data analysis: An expanded sourcebook. sage.

Mortelmans, D., \& Verheyen, W. (2011). A dyadic view on the postseparation network of single mothers. Qualitative Sociology Review, 7(3).

Romo, L. F., Bravo, M., \& Tschann, J. M. (2014). The effectiveness of a joint mother-daughter sexual health program for Latina early adolescents. Journal of Applied Developmental Psychology, 35(1), 1-9.

Russell, B. S., \& Guite, J. W. (2020). Parenting impacts from a mindfulness-based pilot intervention for families facing pediatric chronic pain. Journal of Child and Family Studies, 29(7), 1861-1872.

Sanders, M. R. (2012). Development, evaluation, and multinational dissemination of the Triple P-Positive parenting program. Annual Review of Clinical Psychology, 8, 345-379.

Schinke, S. P., Fang, L., Cole, K. C., \& Cohen-Cutler, S. (2011). Preventing substance use among Black and Hispanic adolescent girls: Results from a computer-delivered, mother-daughter intervention approach. Substance use \& misuse, 46(1), 35-45.

Sieving, R. E., McRee, A. L., McMorris, B. J., Shlafer, R. J., Gower, A. L., Kapa, H. M., \& Resnick, M. D. (2017). Youth-adult 
connectedness: A key protective factor for adolescent health. American journal of preventive medicine, 52(3), S275-S278.

Snyderman, N., \& Streep, P. (2002). Girl in the mirror: Mothers and daughters in the years of adolescence. New York: Hyperion

Strauss, A., \& Corbin, J. M. (1997). Grounded Theory in Practice. Sage.

Thomson, E., \& McLanahan, S. S. (2012). Reflections on "Family structure and child well-being: Economic resources vs. parental socialization". Social Forces, 91(1), 45-53.

U.S. Census Bureau (2021). 2012-2016 American Community Survey 5-year Estimates. Retrieved from https://www.census.gov/progra ms-surveys/acs/technical-documentation/table-and-geographychanges/2016/5-year.html.

Vespa, J., Lewis, J. M., \& Kreider, R. M. (2013). America's families and living arrangements: 2012. Current population reports, 20(2013), P570.
Waldfogel, J., Craigie, T.-A., \& Brooks-Gunn, J. (2010). Fragile families and child wellbeing. The Future of Children/Center for the Future of Children, the David and Lucile Packard Foundation, 20(2), 87.

Walsh, F. (2016). Family resilience: a developmental systems framework. European Journal of Developmental Psychology, 13(3), 313-324.

Wang, C., Liu, J. L., Havewala, M., Zhu, Q., Do, K. A. \& Shao, X. (2021). Parent-Child Connect: A culturally responsive parent training for Asian American parents at school. Psychology in the Schools, 58(8), 1624-1641.

Wei, H. S., Shih, A. T., Chen, Y. F. \& Hong, J. S. (2020). The impact of adolescent parentification on family relationship and civicengagement. Journal of Social Work, 21(6), 1413-1432. 